\title{
Acoustic Noise in Moscow during the Covid-19 Quarantine Period in 2020
}

\author{
A. A. Spivak ${ }^{a}$, , D. N. Loktev ${ }^{a}$, Yu. S. Rybnov ${ }^{a}$, and V. A. Kharlamov ${ }^{a}$ \\ Presented by Academician V.V. Adushkin July 13, 2020
}

Received September 25, 2020; revised October 19, 2020; accepted October 19, 2020

\begin{abstract}
This paper addresses the results of instrumental observation of acoustic oscillations in the atmosphere above the city of Moscow during the COVID-19 quarantine period. Instrumental observations made by the Geophysical Monitoring Center (GMC) at the Institute of Geosphere Dynamics (IGD), Russian Academy of Sciences, show that the quarantine-related decrease in production activity caused significant changes in the amplitude and spectral characteristics of acoustic noise above the city, as compared to the long-term averages. During the quarantine period, the amplitude of the main spectral components and the average amplitude of acoustic noise decreased by more than two times. The diurnal variation of the amplitude of noise caused by production activities in the daytime was much less evident. Our findings can be useful in determining the characteristics of technogenic noise sources and assessing its contribution to the total acoustic noise level of the city.
\end{abstract}

Keywords: COVID-19, production activities, acoustic noise

DOI: $10.1134 / \mathrm{S} 1028334 \mathrm{X} 21010232$

The eco-environment in large urban agglomerations is disturbed by anthropogenic activities, as well as natural phenomena and processes [1]. The COVID-19 quarantine in the spring of 2020 provided a unique opportunity to assess the contribution of the technogenic activities to the overall negative effect on the characteristics of the geophysical environment in megalopolises. Available publications indicate a noticeable decrease in the level of seismic noise during the COVID-19 period [2-4].

Acoustic noise is one of the main factors that negatively affect the human body [5-8]. Numerous anthropogenic sources of noise associated with production, construction, and transportation activities make a significant contribution to the acoustic load on the human environment in megalopolises [9]. In order to determine the characteristics of technogenic sources of noise and assess their contribution to the total acoustic noise, it is necessary to study the characteristics of acoustic noise in a megalopolis. This information will provide a database for solving applied and fundamental problems, too. One of the largest megacities in the world, Moscow is characterized by high

\footnotetext{
${ }^{a}$ Sadovskii Institute of Geosphere Dynamics, Russian Academy of Sciences, Moscow, 119334 Russia

*e-mail: aaspivak100@gmail.com
}

noise levels. During the quarantine period for COVID-19, Moscow suspended the activities of most industrial enterprises unrelated to city maintenance. This, in turn, led to a significant decrease in the road and rail traffic.

This paper examines the parameters of acoustic noise generated by Moscow during the quarantine period, as compared to the preceding period.

We use series of instrumental observations of micropulsations of atmospheric pressure above Moscow, which have been made by the Geophysical Monitoring Center, Institute of Geosphere Dynamics, Russian Academy of Sciences (GMC, IGD) ${ }^{1}$ since 2014 [10]. Micropulsations of atmospheric pressure $P$ (acoustic oscillations) have been recorded in the frequency ranges from 0.05 to $30 \mathrm{~Hz}$ and from 0.001 to $10 \mathrm{~Hz}$ using MB-02 and MB-03 microbarometers, respectively [11]. At the same time, a Davis Vantage Pro2 digital automatic weather station has recorded meteorological parameters, such as wind velocity, air temperature and humidity, atmospheric pressure, and other phenomena the characteristics of which provide additional information about the surface atmosphere.

The records in the form of digital series $P(t)$ have been accumulated on hard disks and posted on the

\footnotetext{
${ }^{1}$ The Geophysical Monitoring Center $\left(55.70^{\circ} \mathrm{N} ; 37.57^{\circ} \mathrm{E}\right)$ is on Leninskii prospekt, Moscow.
} 


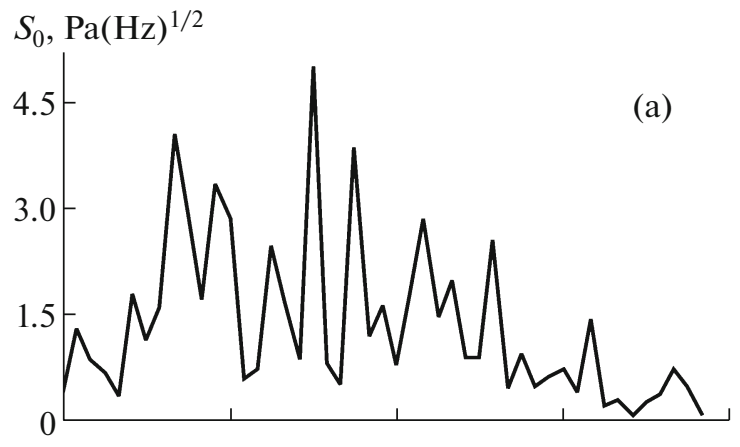

$S_{C}, \mathrm{~Pa}(\mathrm{~Hz})^{1 / 2}$

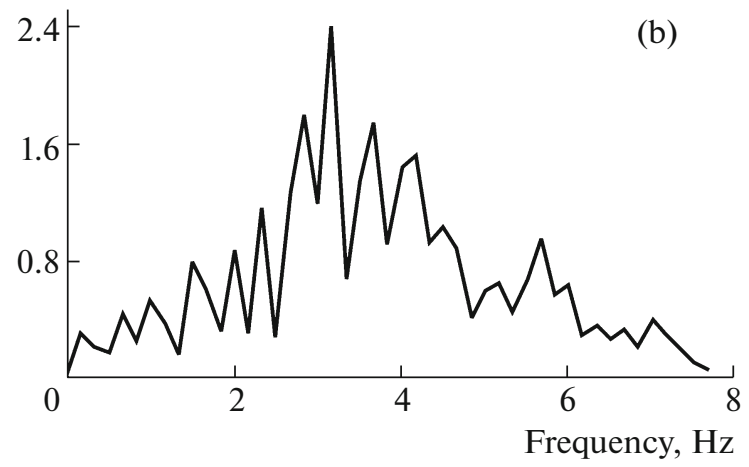

Fig. 1. Spectra of acoustic oscillations in Moscow, based on GMC data: (a) March 20 to March 24, 2020 (no quarantine); and (b) May 20 to May 24, 2020 (quarantine).

website of the IGD (www.idg-copm.chph.ras.ru) in graphic and digital forms. We analyzed data from February to May 2020 obtained in periods with similar wind characteristics (wind velocity from 3 to $6 \mathrm{~m} / \mathrm{s}$ ) and calm meteorological conditions, i.e., with no strong atmospheric disturbances such as hurricanes, strong gusts, and atmospheric fronts.

It was found from analysis of the instrumental observation data that a decrease in traffic and the cessation of activities for a significant number of industrial enterprises and organizations in Moscow during the quarantine period resulted in a noticeable change in the amplitude and spectral characteristics of urban acoustic noise. Figure 1 shows the spectra of acoustic noise in the frequency range that is most important for humans, based on the instrumental observations during the quarantine period $\left(S_{C}\right)$ and before it $\left(S_{0}\right)$.

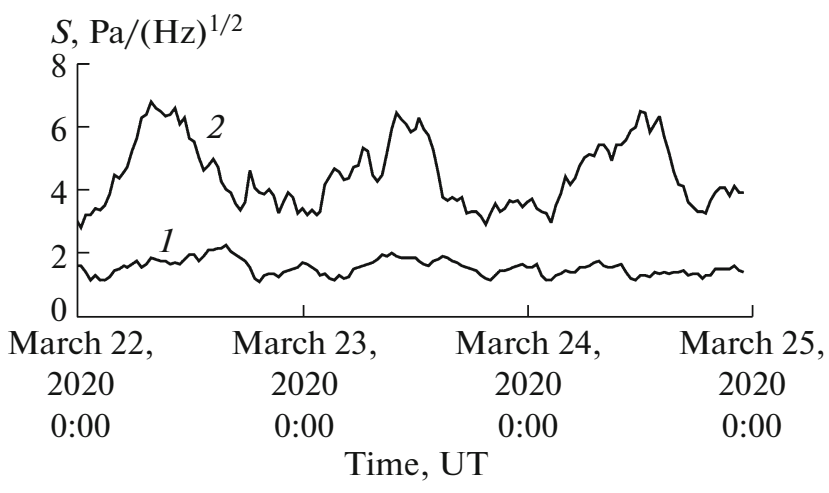

Fig. 2. Diurnal variation of the amplitude of the spectral density at a frequency of $3 \mathrm{~Hz}$ : (1) from May 22 to May 24, 2020 (quarantine); and (2) from March 22 to March 24, 2020 (no quarantine).

Clearly, the maximum values of the spectral density of acoustic oscillations are in the frequency range from 1 to $6.5 \mathrm{~Hz}$ for both periods. However, while the period preceding the quarantine is characterized by several spectral maxima with frequency $f_{0}$ in the range from 1.3 to $6.3 \mathrm{~Hz}$ and spectral amplitude $S_{0}$ from 1.4 to $5 \mathrm{~Pa} /(\mathrm{Hz})^{1 / 2}$ (Table 1 ), the acoustic noise spectrum during the quarantine has a smaller number of spectral peaks with frequency $f_{C}$ close to $f_{0}$ in a narrower frequency range from 2.5 to $5.1 \mathrm{~Hz}$ and with spectral amplitudes $S_{C}$ significantly lower than $S_{0}$.

The change in the spectral characteristics was accompanied by changes in the diurnal variation of the amplitudes of different spectral maxima $S$. Figures 2 and 3 show $S(t)$ for frequencies of 3 and $5 \mathrm{~Hz}$ for the quarantine period and the preceding period, respectively.

It follows from the figures that the spectral amplitudes at frequencies of 3 and $5 \mathrm{~Hz}$ during the quarantine are approximately two times lower than those before the quarantine; the daily periodicity is much less distinct.

In summary, the quarantine significantly reduced the technogenic acoustic load on Moscow: the amplitude of acoustic oscillations decreased and their frequency range narrowed. Importantly, the amplitude characteristics of acoustic noise during the quarantine

Table 1. Spectral characteristics of acoustic noise in Moscow (Leninskii prospekt) during the COVID-19 quarantine and in the previous period

\begin{tabular}{c|c|c|c|c|c|c|c|c|c}
\hline Period & \multicolumn{1}{c}{ Parameters } \\
\hline from March 20 to March 24, 2020 & $f_{0}, \mathrm{~Hz}$ & 1.3 & 1.8 & 2.5 & 3.0 & 3.5 & 4.3 & 5.1 & 6.3 \\
& $S_{0}, \mathrm{~Pa} /(\mathrm{Hz})^{1 / 2}$ & 4.1 & 3.4 & 2.5 & 5.0 & 3.8 & 2.8 & 2.5 & 1.4 \\
\hline from May 20 to May 24, 2020 & $f_{C}, \mathrm{~Hz}$ & - & - & 2.8 & 3.1 & 3.6 & 4.1 & 5.6 & - \\
& $S_{C}, \mathrm{~Pa} /(\mathrm{Hz})^{1 / 2}$ & - & - & 1.8 & 2.4 & 1.7 & 1.5 & 1.0 & - \\
\hline
\end{tabular}




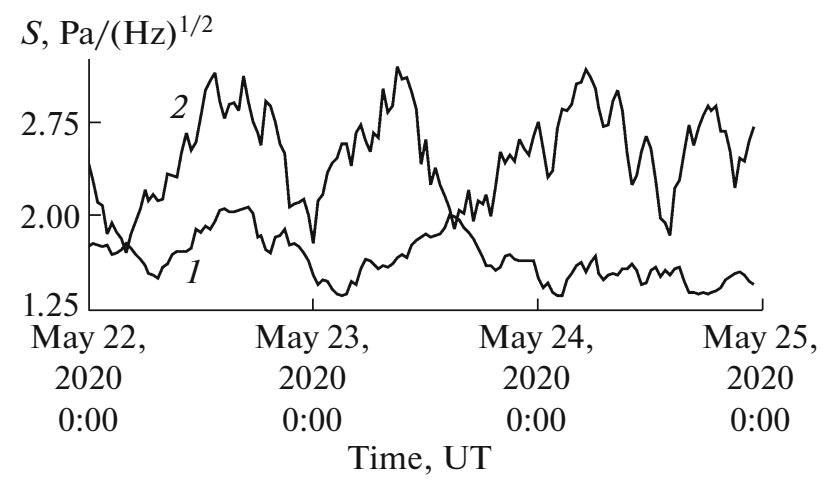

Fig. 3. Diurnal variation of the amplitude of the spectral density at a frequency of $5 \mathrm{~Hz}$ : (1) from May 22 to May 24, 2020 (quarantine) and (2) from March 22 to March 24, 2020 (no quarantine).

period remained almost unchanged (practically constant in the frequency area around $3 \mathrm{~Hz}$ ), while periods of intensive economic activity are characterized by more distinct daily periodicities due to intense traffic during the day and the fact that most industrial enterprises are closed at night. Our findings can be useful in assessing the quantitative contribution of man-made noise, based on comparison of the amplitude-frequency characteristics of acoustic noise during the quarantine period with those in the preceding period.

\section{ACKNOWLEDGMENTS}

This study was conducted under a State Assignment, project no. AAAA-A-19-119021890067-0.

\section{REFERENCES}

1. V. V. Adushkin and A. A. Spivak, Nauka Ross., No. 5, 65-69 (1995).

2. T. Lecocq, S. P. Hicks, K. V. Noten, et al., Science 369 (6509), 1338-1343 (2020).

3. P. Poil, J. Boaga, I. Molinari, V. Cascone, and L. Boschi, Sci. Rep. 10 (1) (2020).

https://doi.org/10.1038/s41598-020-66368-0

4. S. N. Somala, Nat. Hazards 103 (1) (2020). https://doi.org/10.1007/s11069-020-04045-1

5. Yu. S. Rybnov and V. A. Kharlamov, in Dynamical Processes in the Internal and External Earth's Shells. Geophysics of Strong Perturbations (Inst. Geosphere Dynamics RAS, Moscow, 1995), pp. 236-244 [in Russian].

6. A. G. Kolesnik, S. V. Pobachenko, and A. V. Solov'ev, Geofiz. Protsessy Biosfera 12 (1), 70-82 (2013).

7. Z. M. Damijan and Jj. Wiciak, Mol. Quantum Acoust. 26, 61-74 (2005).

8. G. Leventhall, P. Pelmear, and S. Benton, Rep. Defra (2003), No. EPG 1/2/50.

9. A. A. Spivak, Yu. S. Rybnov, and V. A. Kharlamov, Geofiz. Protsessy Biosfera 18 (1), 118-124 (2019).

10. A. A. Spivak, S. B. Kishkina, D. N. Loktev, Yu. S. Rybnov, S. P. Solov'ev, and V. A. Kharlamov, Seism. Prib. 52 (2), 65-78 (2016).

11. Yu. S. Rybnov, V. A. Kharlamov, and V. F. Evmenov, in Dynamical Processes in the System of Internal and External Interacting Waves (GEOS, Moscow, 2005), pp. 2933 [in Russian].

Translated by B. Shubik 